\title{
Characteristic Cytological Features of Cervical Clear Cell Adenocarcinoma: A Report of 4 Cases
}

\author{
Kenzo Sonoda ${ }^{1 *}$, Miwako Nogami ${ }^{2}$, Masaki Naka ${ }^{2}$, Fumihiko Ookubo ${ }^{2}$, Hiroaki Kobayashi ${ }^{1}$, Hideaki Yahata ${ }^{1}$, Kaoru Okugawa $^{1}$, Eisuke \\ Kaneki $^{1}$, Yoshinao Oda ${ }^{3}$ and Kiyoko Kato ${ }^{1}$ \\ ${ }^{1}$ Department of Obstetrics and Gynecology, Graduate School of Medical Sciences, Kyushu University, Fukuoka 812-8582, Japan \\ 2Division of Diagnostic Pathology, Kyushu University Hospital, Fukuoka 812-8582, Japan \\ ${ }^{3}$ Department of Anatomic Pathology, Graduate School of Medical Sciences, Kyushu University, Fukuoka 812-8582, Japan
}

\begin{abstract}
We experienced 5 cases of clear cell adenocarcinoma (CCAC) of the cervix in the 10-year period from 2003 to 2012. Because a specimen from one of the cases was poorly preserved, we analyzed cytological features of the 4 remaining cases. Characteristic large, pale-staining atypical cells with prominent, round nuclei were seen in all cases. Additionally, a hobnail appearance and basement membrane-like substance were detected in 3 cases, and a mirror ball cluster-like morphology was found in 1 case. Cervical CCAC has been reported to be difficult to diagnose by cytology; however, we were able to diagnose these 4 cases by recognizing several characteristic cytological features.
\end{abstract}

Keywords: Uterine cervix; Clear cell adenocarcinoma; Cytology; PAS

\section{Introduction}

Clear cell adenocarcinoma (CCAC) of the cervix is a rare neoplasm that accounts for only $2-7 \%$ of cervical adenocarcinomas [1]. Several studies have reported that cervical and vaginal CCAC in young women is associated with intrauterine exposure to the synthetic nonsteroidal estrogen hormone diethylstilbestrol (DES), which is prescribed as a preventive therapy against abortion $[2,3]$. On the other hand, many reports have described the occurrence of cervical and vaginal CCAC without history of exposure to DES [4]. A retrospective review was conducted to provide insight into the management of CCAC in the post-DES era between 1982 and 2004 in the USA [5]. CCAC was confirmed in 34 patients having a median age of 53 years. Moreover, Reich et al. reported that the clinicopathological findings and prognosis of surgically treated patients with stage IB-IIB clear cell carcinomas without exposure to DES were similar to those of patients with squamous cell carcinomas and non-clear cell adenocarcinomas [6].

Although the cytological findings of cervical CCAC have been studied relatively well, it remains difficult to diagnose cervical CCAC by cytological examination [7]. We experienced 5 cases of CCAC of the cervix without a history of DSE exposure in the past 10 years. In order to contribute to a better understanding and correct diagnosis of cervical CCAC, we evaluated the cytological features of 4 of these cases; 1 case was excluded due to poor preservation of the specimen.

\section{Case reports}

\section{Case 1}

A 70-year-old woman (gravida 2, para 2) did not participate in the routine cervical cancer screening and consulted a local clinic because of genital bleeding. Because cervical cancer was suspected, she was referred to our hospital. Speculum examination revealed that the cervix was replaced by necrotic tumor tissue and enlarged to $5 \mathrm{~cm}$ in diameter. The upper one-third of the vagina was invaded, but there was no sign of parametrial involvement. Serum squamous cell carcinoma antigen was elevated to $2.5 \mathrm{ng} / \mathrm{mL}$. Cytological findings indicated adenocarcinoma, and histological diagnosis by punch biopsy further indicated CCAC. With a diagnosis of stage IIA2 cervical cancer, radiation therapy (whole pelvis irradiation $45 \mathrm{~Gy}$, and intracavitary brachytherapy $24 \mathrm{~Gy}$ ) was performed because the patient was also affected by diabetes mellitus with renal dysfunction. A recurrent tumor was detected in the cervix at 14 months after the end of treatment, and the patient was given only palliative care thereafter.

\section{Case 2}

A 78-year-old woman (gravida 3, para 3) did not participate in the routine cervical cancer screening and complained of postmenopausal genital bleeding. Speculum examination revealed that a smooth-surfaced small mass protruded from the external os. The cervix was pigeon-egg sized and firm, but no other abnormal findings were detected in the uterine corpus and ovaries. An ultrasound scan showed an irregularly margined mass $4 \mathrm{~cm}$ in diameter in the lower part of the uterus. Both cervical and endometrial cytological findings indicated adenocarcinoma, and histological diagnosis revealed CCAC. Serum carcinoembryonic antigen was elevated to $4.1 \mathrm{ng} / \mathrm{mL}$. With a pre-operative diagnosis of endometrial cancer, total abdominal hysterectomy, bilateral salpingooophorectomy, pelvic and para-aortic lymphadenectomy, and omentectomy were performed. Macroscopic findings revealed that the tumor originated from the cervix, with fullthickness stromal invasion. Adjuvant treatment was recommended because of lymph node metastases; however, the patient refused treatment and died due to recurrence.

\section{Case 3}

A 66-year-old woman (gravida 3, para 1) did not participate in

*Corresponding author: Kenzo Sonoda, Department of Obstetrics and Gynecology, Graduate School of Medical Sciences, Kyushu University, Maidashi 3-1-1, Higashi-ku, Fukuoka 812-8582, Japan, Tel: 81-92-642-5395; Fax: 81-92642-5414; E-mail: kenzo@med.kyushu-u.ac.jp

Received October 29, 2013; Accepted November 20, 2013; Published November 22, 2013

Citation: Sonoda K, Nogami M, Naka M, Ookubo F, Kobayashi H, et al. (2013) Characteristic Cytological Features of Cervical Clear Cell Adenocarcinoma: A Report of 4 Cases. J Cytol Histol 4: 196. doi: 10.4172/2157-7099.1000196

Copyright: ( 2013 Sonoda K, et al. This is an open-access article distributed under the terms of the Creative Commons Attribution License, which permits unrestricted use, distribution, and reproduction in any medium, provided the original author and source are credited. 
Citation: Sonoda K, Nogami M, Naka M, Ookubo F, Kobayashi H, et al. (2013) Characteristic Cytological Features of Cervical Clear Cell Adenocarcinoma: A Report of 4 Cases. J Cytol Histol 4: 196. doi: 10.4172/2157-7099.1000196

the routine cervical cancer screening and had a medical examination because of genital bleeding. The cervix was firmly enlarged at over 3 $\mathrm{cm}$ in diameter, and cytological diagnosis indicated adenocarcinoma. Pathological findings from endocervical canal curretage revealed CCAC; however, no extra-uterine invasion or metastasis was detected by both pelvic and imaging examinations. A radical abdominal hysterectomy was performed for pre-operative diagnosis of cervical cancer stage IB1. Cancerous tissue originated from the cervix, with a mass of $6.5 \mathrm{~cm}$ in diameter. Six courses of adjuvant chemotherapy were performed using paclitaxel and carboplatin. The patient received follow-up in an out-patient clinic without recurrence.

\section{Case 4}

A 42-year-old woman (gravida 3, para 2) was referred to our hospital because of an abnormal Pap test (atypical glandular cells). Cervical erosion with a tendency to bleed was revealed by speculum examination, but no other abnormal findings were detected by physical examination. Cytological findings revealed adenocarcinoma, and histological diagnosis by punch biopsy further indicated CCAC. Preoperative diagnosis was carcinoma colli stage IB1, and the patient underwent a radical abdominal hysterectomy. The pathological diagnosis of the resected uterus was CCAC of the cervix without extrauterine extension. Carcinoma cells with clear cytoplasm proliferated in a tubulocystic pattern. The stromal invasion was $11 \mathrm{~mm}$ in width and $2 \mathrm{~mm} / 10 \mathrm{~mm}$ in depth without lymphovascular permeation. Postoperative adjuvant therapy was not performed, and the patient was followed-up without recurrence.

\section{Cytological findings}

Pre-operative cytological diagnosis was adenocarcinoma in all 4 cases. Therefore, we evaluated cytological findings again in preparation for this manuscript. Cervical cytology showed clusters of adenocarcinoma cells of unequal sizes in which the nuclear/cytoplasmic ratio was high (Figure 1 and Table 1). Sheet-like arrangements of
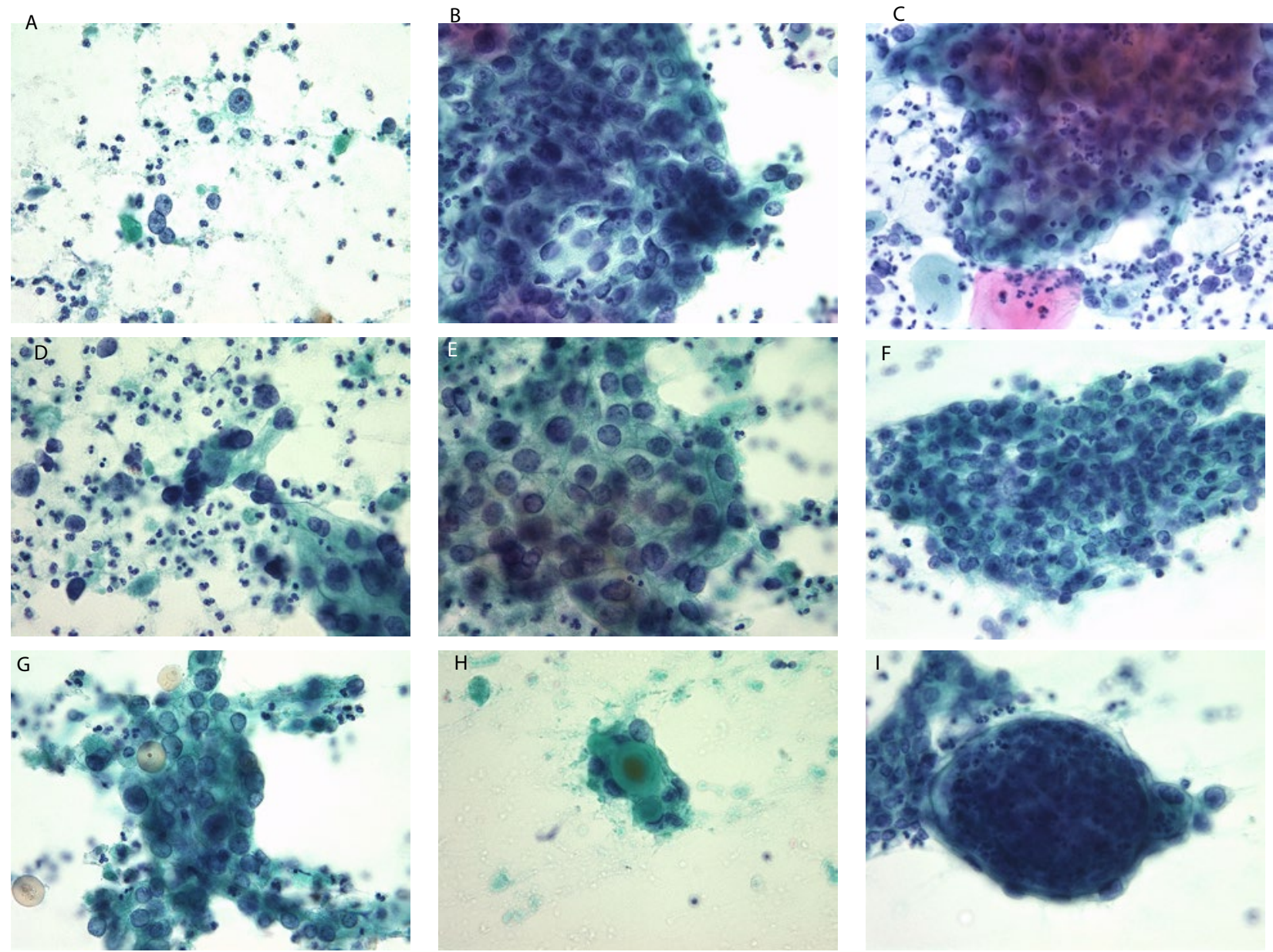

Figure 1: Cytological findings in Papanicolaou-stained smears (original objective magnification: 40x). a: Eosinophilic conspicuous nucleoli (case 1).

b: Fine granular chromatin (case 4).

c: Round/oval nuclei (case 4).

d: Naked nucleus-like cells (case 3).

e: Abundant translucent cytoplasm (case 3).

f: Sheet-like arrangement (case 4).

$\mathrm{g}$ : Hobnail/peg-shaped appearance (case 1).

h: Basement membrane-like substance (case 2).

i: Mirror ball cluster (case 4). 
Citation: Sonoda K, Nogami M, Naka M, Ookubo F, Kobayashi H, et al. (2013) Characteristic Cytological Features of Cervical Clear Cell Adenocarcinoma: A Report of 4 Cases. J Cytol Histol 4: 196. doi: 10.4172/2157-7099.1000196

Page 3 of 4

\begin{tabular}{|c|c|c|c|c|}
\hline Clinicopathological variables & Case 1 & Case 2 & Case 3 & Case 4 \\
\hline $\begin{array}{l}\text { Stage } \\
\text { Pathological finding }\end{array}$ & $\begin{array}{l}\text { IIA2 } \\
\text { papillary }\end{array}$ & $\begin{array}{c}\text { IB2 } \\
\text { tubulocystic }\end{array}$ & $\begin{array}{l}\text { IB1 } \\
\text { tubulocystic }\end{array}$ & $\begin{array}{l}\text { IB1 } \\
\text { tubulocystic }\end{array}$ \\
\hline Cytological finding* in Papanicolaou-stained smear & & & & \\
\hline Eosinophilic conspicuous nucleolus & + & + & + & + \\
\hline Fine granular chromatin & + & + & + & + \\
\hline Round/oval nucleus & + & + & + & + \\
\hline Naked nucleus-like cell & + & + & + & + \\
\hline Abundant translucent cytoplasm & + & + & + & + \\
\hline Sheet-like arrangement & + & + & + & + \\
\hline Hobnail/peg-shaped appearance & + & + & + & - \\
\hline Basement membrane-like substance & + & + & + & - \\
\hline Mirror ball cluster & - & - & - & + \\
\hline
\end{tabular}

* +: positive; -: negative

Table 1: Cytological features of the 4 cases.
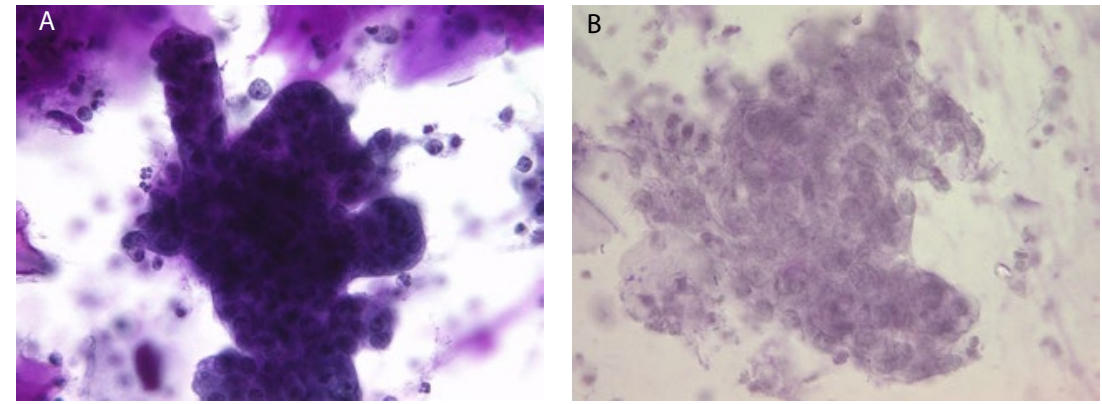

Figure 2: The cytoplasm was positive for the PAS reaction in case 4, but was digested by diastase (original objective magnification: 40x). a: PAS reaction without diastase treatment (case 4 ).

b: PAS reaction after diastase treatment (case 4).

atypical cells, but not three-dimensional clusters, were mainly detected. Atypical cells had abundant pale-staining translucent cytoplasms, with distinct cell borders. A portion of the cells had vacuolated cytoplasms. The nuclei were round and oval, and large, conspicuous eosinophilic nucleoli and fine granular chromatin were observed within the nuclei. Many dispersed atypical cells presented as naked nuclei. Three cases had characteristic outward protrusion of pleomorphic nuclei at the periphery of sheet-like arrangements, i.e., so-called "hobnail or pegshaped appearance". Globular, hyaline basement membrane-like substances, either naked or surrounded by neoplastic epithelial cells, were also detected in 3 cases. However, a mirror ball cluster-like morphology was found in only 1 case. The cytoplasm was positive for periodic acid-Schiff (PAS) reaction, but was digested by diastase (Figure 2).

\section{Discussion}

CCAC of the cervix is a rare malignancy. The Japan Society of Obstetrics and Gynecology reported 32 cases of CCAC $(0.4 \%$ of all cervical cancer cases; $2.5 \%$ of adenocarcinoma cases) in Japan in 2011 [8]. We experienced 5 CCAC cases without exposure to DES over the past 10 years. CCAC occurrence at our institution accounted for $0.6 \%$ of all cervical cancer cases and $3.0 \%$ of all adenocarcinomas, similar to the international incidence. There have been numerous reports describing the clinicopathological variables and prognosis of cervical CCAC. Some studies have reported that the prognosis of CCAC patients is similar to that of patients with squamous cell carcinoma [6]; however, other reports have shown that CCAC prognosis is poorer than that of other types of cervical cancers due to recurrence of cervical CCAC following chemotherapy and radiation [9]. To help achieve better prognoses in cervical CCAC, earlier diagnosis will be necessary.

The sensitivity of cytological examinations in the detection of cervical CCAC has been advocated in various publications [10], and doubts about its diagnostic value have also been expressed. One study found that $25 \%$ of cases of CCAC presented with false-negative smears [11]. On the other hand, Hanselaar et al. reported that cytopathological examinations were informative in $85 \%$ of cervical CCAC and claimed that patients were appropriately surveyed by clinical and cytological examinations [12]. Several cytological findings have been reported for CCAC of the cervix [13-15]. The cells show abundant, pale-stained, translucent cytoplasm. They have round or oval nuclei localized almost in the center of the cell, and these nuclei contain single, eosinophilic, prominent nucleoli. The appearance of diffuse, large, naked nuclei has also been reported as characteristic of cervical CCAC. Each of these findings was also detected in our 4 patients. However, it is difficult to diagnose CCAC based only on these cytological findings. Several other tumors and tumor-like lesions of the female genital tract may also contain clear cells and may occasionally be misinterpreted as CCAC [16]. Nadji et al. observed a hobnail appearance in a specimen of CCAC of the vagina obtained by fine needle aspiration [17]. Additionally, Nishida et al. reported a mirror ball cluster-like morphology on aspiration cytology of ascites in a patient with CCAC of the ovary and proposed that this finding is a characteristic cytological feature of CCAC [18]. A positive cytoplasmic PAS reaction that can be digested by diastase is also a diagnostic clue to CCAC [7]. Of our 4 cases, 3 exhibited a hobnail/ peg-shaped appearance, while 1 exhibited a mirror ball cluster-like morphology. Few previous reports have described the hobnail/pegshaped appearance and mirror ball cluster-like morphology observed on cytological examination of cervical scraping smears. This may be because histological structures are not well preserved in scraping smears compared to needle aspiration cytology. 
Citation: Sonoda K, Nogami M, Naka M, Ookubo F, Kobayashi H, et al. (2013) Characteristic Cytological Features of Cervical Clear Cell Adenocarcinoma: A Report of 4 Cases. J Cytol Histol 4: 196. doi: 10.4172/2157-7099.1000196

\section{Conclusion}

CCAC of the cervix has been reported to be difficult to diagnose by cytology; however, we were able to diagnose CCAC of the cervix by recognizing the characteristic cytological features mentioned above.

\section{Acknowledgments}

We thank Ms. Emiko Hori for technical assistance. This work was supported in part by a grant-in-aid for scientific research from the Japan Society for the Promotion of Science (No. 24592519) and Suzuken Memorial Foundation.

\section{References}

1. Yabushita H, Kanyama K, Sekiya R, Noguchi M, Wakatsuki A (2008) Clear-cell adenocarcinoma of the uterine cervix in a 17-year-old adolescent. Int $\mathrm{J}$ Clin Oncol 13: 552-554

2. Greenwald P, Barlow JJ, Nasca PC, Burnett WS (1971) Vaginal cancer after maternal treatment with synthetic estrogens. N Engl J Med 285: 390-392.

3. Hertrich O (1973) Clear cell adenocarcinoma in young females. Obstet Gynecol 41: $494-500$

4. Boyd J, Takahashi H, Waggoner SE, Jones LA, Hajek RA, et al. (1996) Molecular genetic analysis of clear cell adenocarcinomas of the vagina and cervix associated and unassociated with diethylstilbestrol exposure in utero. Cancer 77: 507-513.

5. Thomas MB, Wright JD, Leiser AL, Chi DS, Mutch DG, et al. (2008) Clear cell carcinoma of the cervix: a multi-institutional review in the post-DES era. Gynecol Oncol 109: 335-339.

6. Reich O, Tamussino K, Lahousen M, Pickel H, Haas J, et al. (2000) Clear cell carcinoma of the uterine cervix: pathology and prognosis in surgically treated stage IB-IIB disease in women not exposed in utero to diethylstilbestrol. Gynecol Oncol 76: 331-335.

7. Suzuki M, Sugiura Y, Machida S, Kohmura Y, Kawano T, et al. (2002) Pale cells in a cervical smear. Cytopathology 13: 171-174.

8. Gynecological cancer board (2012) Gynecological cancer incidence in 2011. Acta Obstet Gynaecol Jpn 64: 2340-2388.
9. Seki H, Takada T, Sodemoto T, Hoshino H, Saitoh K, et al. (2003) A young woman with clear cell adenocarcinoma of the uterine cervix. Int $\mathrm{J}$ Clin Oncol 8: 399-404.

10. Hanselaar A, van Loosbroek M, Schuurbiers O, Helmerhorst T, Bulten J, et al. (1997) Clear cell adenocarcinoma of the vagina and cervix. An update of the central Netherlands registry showing twin age incidence peaks. Cancer 79 2229-2236.

11. Robboy SJ, Kaufman RH, Prat J, Welch WR, Gaffey T, et al. (1979) Pathologic findings in young women enrolled in the National Cooperative Diethylstilbestro Adenosis (DESAD) project. Obstet Gynecol 53: 309-317.

12. Hanselaar AG, Boss EA, Massuger LF, Bernheim JL (1999) Cytologic examination to detect clear cell adenocarcinoma of the vagina or cervix. Gynecol Oncol 75: 338-344.

13. Saigo PE, Wolinska WH, Kim WS, Hajdu SI (1985) The role of cytology in the diagnosis and follow-up of patients with cervical adenocarcinoma. Acta Cytol 29: 785-794.

14. Hirokawa M, Shimizu M, Nakamura E, Kanahara T, Yamauchi H, et al. (2000) Basement membrane material and tigroid background in a fine needle aspirate of clear cell adenocarcinoma of the cervix. A case report. Acta Cytol 44: 251 254

15. Jimenez-Heffernan JA, Vicandi B, Gonzalez-Peramato P, Perez-Campos A Lopez-Ferrer P, et al. (2004) Cytologic features of clear cell carcinoma of the female genital tract. Diagnostic value of the "raspberry body" in nonexfoliative cytologic specimens. Acta Cytol 48: 47-51.

16. Matias-Guiu X, Lerma E, Prat J (1997) Clear cell tumors of the female genital tract. Semin Diagn Pathol 14: 233-239.

17. Nadji M, Greening SE, Sevin BU, Averette HE, Nordqvist SR, et al. (1979) Fine needle aspiration cytology in gynecologic oncology. II. Morphologic aspects. Acta Cytol 23: 380-388.

18. Nishida M, Kuramoto H, Tatsumi H, Miura T, Arai M (1979) Cytological findings of ascites in patients with ovarian clear cell carcinoma: diagnostic significance and genesis of mirror ball pattern. J Jpn Soc Clin Cytol 18: 280-294. 